\title{
INFLUENCE OF SMALL MICROSCOPIC GROOVES OF WORK ROLLS ON STRAIN GRADIENT INDUCED IN METAL SHEETS DURING SYMMETRIC AND ASYMMETRIC ROLLING
}

\author{
Denis PUSTOVOYTOV, Alexander PESIN, Natalya LOKOTUNINA, Anna KOZHEMIAKINA \\ Nosov Magnitogorsk State Technical University, Magnitogorsk, Russian Federation, \\ pustovoitovden@mail.ru
}

https://doi.org/10.37904/metal.2019.701

\begin{abstract}
Creating of gradient structures with the grain size changing from microns to nano-scale through the thickness of processed metallic materials represents a new advanced strategy for producing a superior combination of high strength and good ductility. Severe plastic deformation with predetermined strain gradient can be considered as a mechanism of creating of gradient structures. Strain gradient through sheet thickness can be achieved by special rolling technique. A surface of work rolls consisted of small microscopic grooves with the depth of $25 \mu \mathrm{m}$, located in transverse to rolling direction. A ribbed surface can have certain advantages in terms of tribological use. When positioned in transverse to metal flow direction a ribbed surface of work rolls can increase the frictional force. The aim of the ribbed surface was to create high opposite frictional forces during rolling and to develop the severe plastic deformation method for producing of sheets and strips with gradient microstructure. This paper presents the distributions of the plastic strain through sheet thickness of pure aluminum processed by symmetric and asymmetric rolling. Effects of contact friction coefficient, thickness reduction per pass and rolls speed ratio were investigated by the rigid-plastic finite element analysis. Extremely high strain difference through sheet thickness was found during symmetric and asymmetric rolling. Finite element analysis of strain gradients can be used for development of the special rolling techniques for fabrication of metal sheets with gradient structures and improved properties.
\end{abstract}

Keywords: Special rolling, microscopic grooves, finite element method, strain gradient, severe plastic deformation

\section{INTRODUCTION}

Aluminium alloys have very attractive features such as lightweight and high specific strength. Efficient way to further increase strength of aluminium alloys is to form an ultrafine grain structure using severe plastic deformation (SPD) methods. However, it usually leads to dramatic loss of ductility of materials. Creating of gradient structures with the grain size changing from microns to nano-scale through the thickness of processed metallic materials represents a new advanced strategy for producing a superior combination of high strength and good ductility. Nature is a rich source of inspiration for the design and fabrication of high-performance materials for different engineering applications [1]. Gradient structures exist overall in the nature in many biological systems, because they have superior properties over homogeneous structures [2]. Recently gradient microstructures were introduced into metallic materials, including steel [3], aluminum [4], copper [5] and other alloys. Severe plastic deformation with predetermined strain gradient can be considered as a mechanism of creating of gradient structures [6-7]. Generally, the gradient microstructure can be produced by surface severe plastic deformation technique, such as sliding friction treatment [8], surface mechanical attrition treatment [9], surface mechanical grinding treatment, high pressure surface rolling [10], skin-pass cold rolling [11]. Strain gradient through sheet thickness can also be achieved by special rolling techniques. For this, incremental rolling processes can be used. Incremental rolling is a process in which the work rolls are structured by small riblets at a size of a few hundred microns [12,13]. Sheet with micro riblets or channels/grooves at surface area can also be produced by micro/meso roll-to-plate (R2P) imprinting process [14]. In the paper [15] the authors 
proposed the rolling process called "Periodical Straining Rolling" or in a short, PSR process that employs the pinion-like or worm-gear-like grooved roll to introduce periodically localized plastic strain in rolled sheet. This process is aimed to control strain distribution to generate microstructure and texture gradient by adapting the proposed process to the conventional strip rolling process. The hot rolling experiment of AZ31 magnesium alloy sheet was conducted with sine curve grooved and continuous arc curve grooved platens to examine the feasibility of the proposed process [15]. As a result, the apparent texture gradients in both the longitudinal and thickness directions were observed from as-PSR processed sheets so that it was proved that the PSR process was able to weaken the (0001) basal texture and increase microstructure evolution of AZ31 sheets [15]. The effects of control of spatial strain distribution on microstructure, micro texture and mechanical properties by using various dimple patterning conditions of PSR process were discussed in paper [16]. The microstructure and micro texture observations of AZ31 magnesium alloy sheets PSR processed under the several dimple patterning conditions (two-sided PSR processing conditions) showed that the weak crystallographic orientations are largely prominent by changing dimple patterning conditions. As a result, the higher Erichsen values can be effectively achieved by changes in dimple patterning as compared to the conventional flat rolling process [16]. Providing of predetermined strain gradient in metallic materials can be achieved by asymmetric rolling, when circumferential speeds of the top and bottom work rolls are different. Asymmetric rolling as a method of severe plastic deformation can be used for grain refinement both in the surface layer and in the core of the processed material [17-20]. So, the gradient microstructure can be produced by surface SPD technique, like special rolling with microscopic grooves of work rolls, and by bulk SPD technique, like asymmetric rolling. The main idea and novelty of this study was the development of combined process, which includes symmetric rolling with microscopic grooves of work rolls and asymmetric rolling for inducing of extremly high strain gradient in Al sheets. The goal of this paper was investigation of the distributions of the plastic strain through sheet thickness of pure aluminum processed by combined process of symmetric and asymmetric cold rolling. Effects of microscopic grooves of work rolls, contact friction coefficient, thickness reduction per pass and rolls speed ratio were investigated by the rigid-plastic finite element analysis.

\section{RESEARCH METHOD}

Numerical simulations allow for detailed process analyzes and thus for process optimization due to minor effort in variation of process parameters. Simulation of the combined rolling process was carried out using the commercial FEM code DEFORM 2D. Combined rolling process consisted of three deformation stages as shown in Figure 1. At the first stage, sheet with initial thickness of $1.0 \mathrm{~mm}$ and one-pass thickness reduction of $10 \%$ was symmetrically rolled by work rolls, which surface consisted of small microscopic grooves, located in transverse to rolling direction. Microscopic grooves had sine profile with the amplitude of $25 \mu \mathrm{m}$ and period of $157 \mu \mathrm{m}$ (Figure 2). FEM model is shown in Figure 3. At the second stage, the riblet surface of the sheet was flattened by smooth work rolls during one-pass thickness reduction of $25 \%$. At the third stage, the sheet was asymmetrically rolled by smooth work rolls during one-pass thickness reduction of $40 \%$. Asymmetry was created due to different circumferential speeds of the work rolls. The top work roll was slower, and the bottom work roll was faster. Rolls speed ratio was varied in the range $10 \ldots 50 \%$ during asymmetric rolling. The final thickness of the sheet was $0.405 \mathrm{~mm}$.

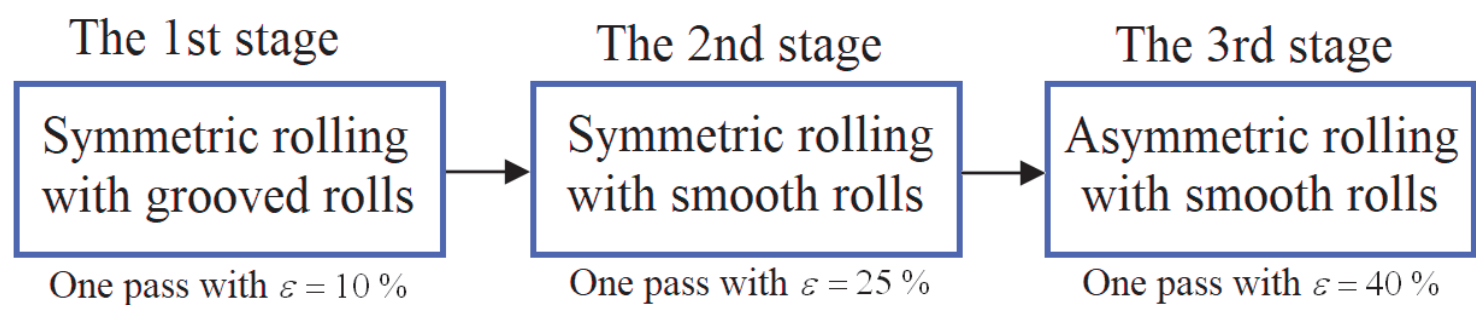

Figure 1 Stages of the combined rolling process 


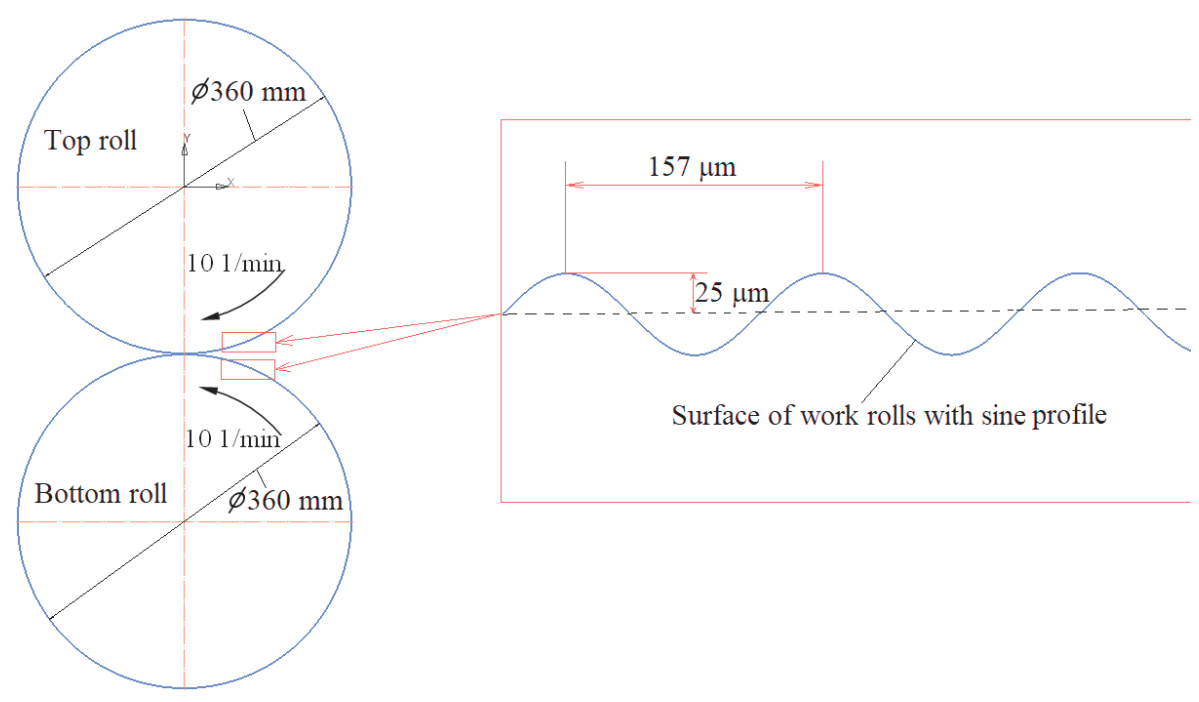

Figure 2 Geometry model of symmetric rolling with microscopic grooves of work rolls

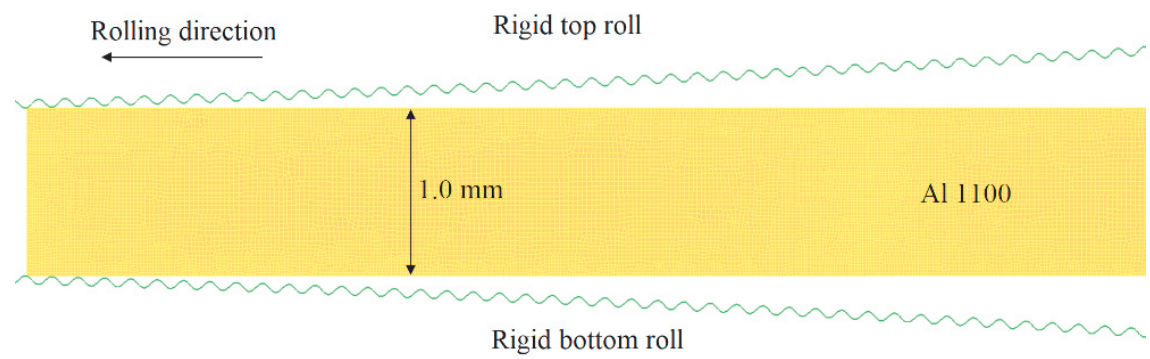

Figure 3 FEM model of symmetric rolling with microscopic grooves of work rolls

The modeling of the process was performed at room temperature without taking into account the increment of the metal's temperature due to the thermal effect of deformation and friction. Pure aluminium Al 1100 was chosen as a hardened rigid-plastic material for the strip. The work rolls were assumed as rigid. The strip with initial thickness of $1.0 \mathrm{~mm}$ and initial length of $30 \mathrm{~mm}$ was meshed with $10000 \ldots 20000$ brick elements. An automatic remeshing was used in all the simulations. The influence of the thickness reduction per pass (10...50 $\%)$, contact friction coefficient $(0.1 \ldots 0.3)$ and rolls speed ratio $(10 \ldots 50 \%)$ on the strain gradient through strip thickness were analyzed in the present study. A Coulomb friction model was used between rolls and strip:

$\tau=f p \leq k$

where:

$\tau$ - frictional stress (MPa)

$f$ - friction coefficient (-)

$p$ - contact pressure (MPa)

$k$ - shear yield stress (MPa)

\section{SIMULATION RESULTS AND DISCUSSION}

It is well known that UFG structure can be obtained by SPD when effective (accumulated) strain $e \geq 4.0$. So, the main idea of this study was the development of cold rolling process, which could provide strain gradient through sheet thickness up to $e \geq 4$.0. Detailed distribution of effective strain through strip thickness after symmetric rolling with grooved rolls is shown in Figure 4. One-pass symmetric rolling with $\varepsilon=10 \%$ and with 
microscopic grooves of work rolls allows very much increase strain up to $e=0.6$ at the surface of the sheet. The rolling at this stage should be performed at low contact friction coefficient (e.g. 0.1) and with low thickness reduction (e.g. $10 \%$ ) in order to prevent folds formation.

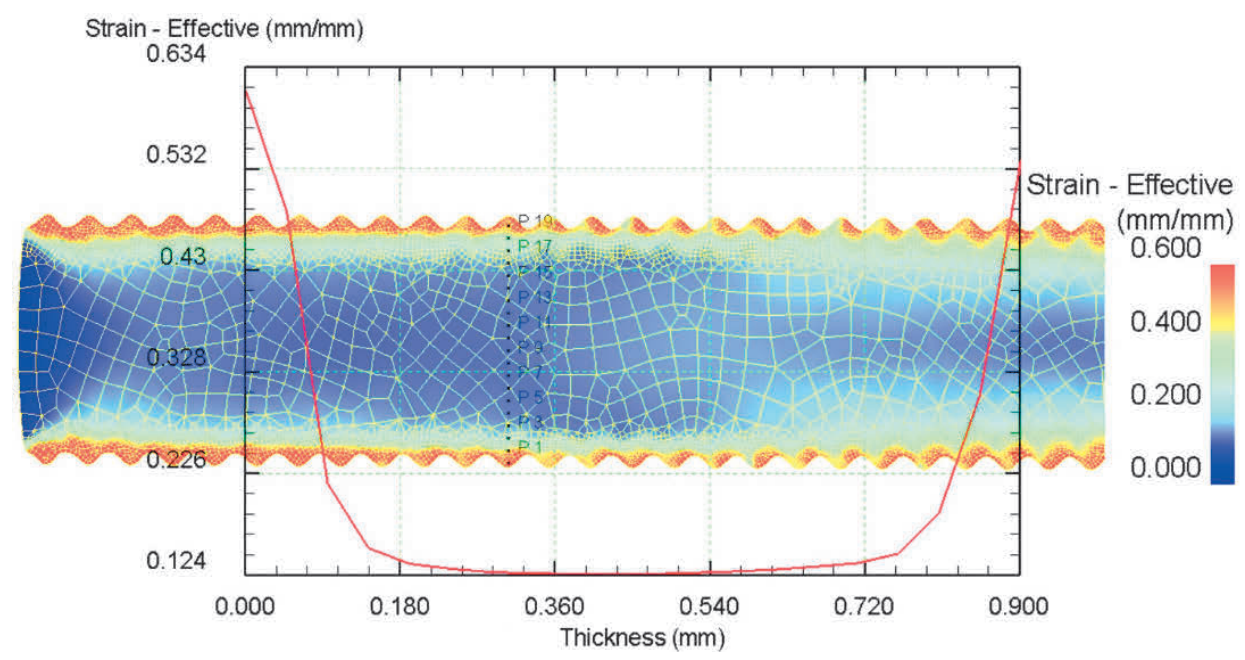

Figure 4 The distribution of effective strain through strip thickness after symmetric rolling with grooved rolls

Detailed distribution of effective strain through strip thickness after symmetric rolling with smooth rolls is shown in Figure 5. The rolling at this stage should also be performed at low contact friction coefficient (e.g. 0.1) in order to prevent folds formation. But thickness reduction should be increased up to $\varepsilon=25 \%$ in order to fully smooth the riblets of the strip.

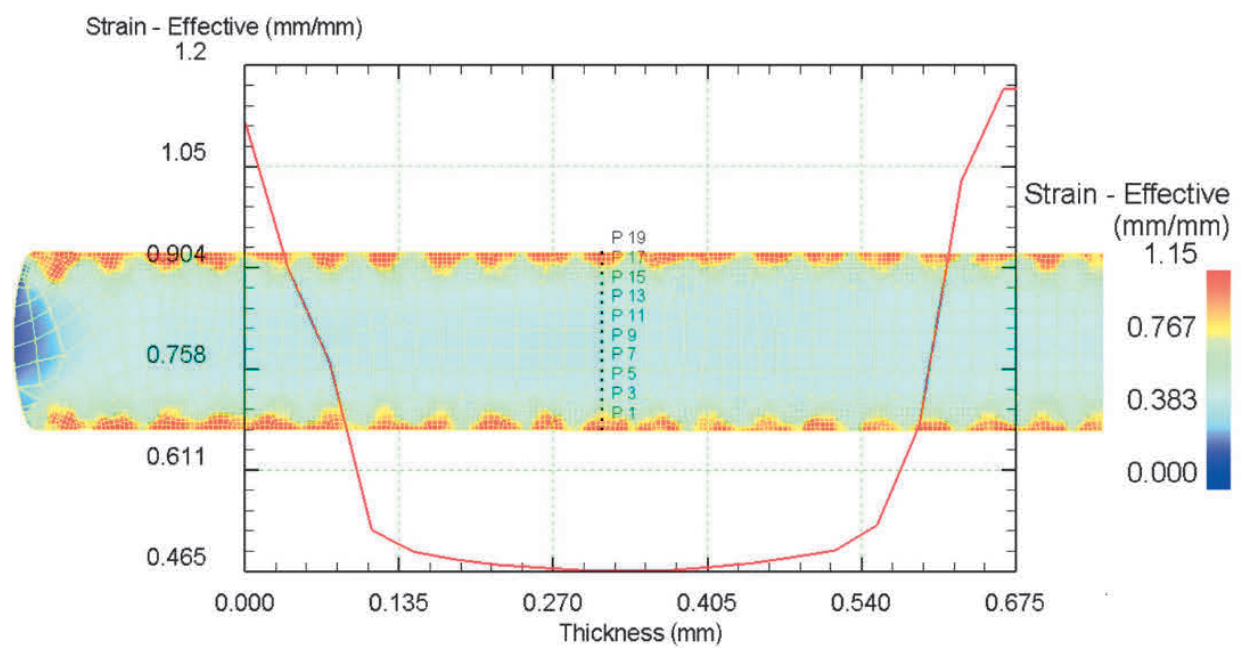

Figure 5 The distribution of effective strain through strip thickness after symmetric rolling with smooth rolls

Searching the optimal process parameters over a wide range of thickness reductions $(10 \ldots 50 \%)$, work rolls speed ratios $(10 \ldots 50 \%)$, friction coefficients $(0.1 \ldots 0.3)$ has shown, that extremely high strain gradient $e \approx 2.0 \ldots 7.2$ through the sheet thickness can be reached, when thickness reduction per pass is very high (e.g. $\varepsilon=40 \%$ ), contact friction coefficient is very high (e.g. 0.3$)$ and the rolls speed ratio is optimal $(\Delta \mathrm{V}=37 \%)$. The distribution of effective strain through strip thickness after asymmetric rolling with smooth rolls is shown in Figure 6. Strain gradient can also be created by conventional (symmetric) rolling with high contact friction. So the different strategies of the rolling processes can be compared (Figure 7). The main disadvantage of the conventional (symmetric) rolling is a low strain gradient $e \approx 1.16 \ldots 1.57$. The simulation results showed that 
extremely high strain gradient through sheet thickness can be reached by combined rolling process consisting of three deformation stages: symmetric rolling with grooved rolls + symmetric rolling with smooth rolls + asymmetric rolling with high rolls speed ratio and a high contact friction.

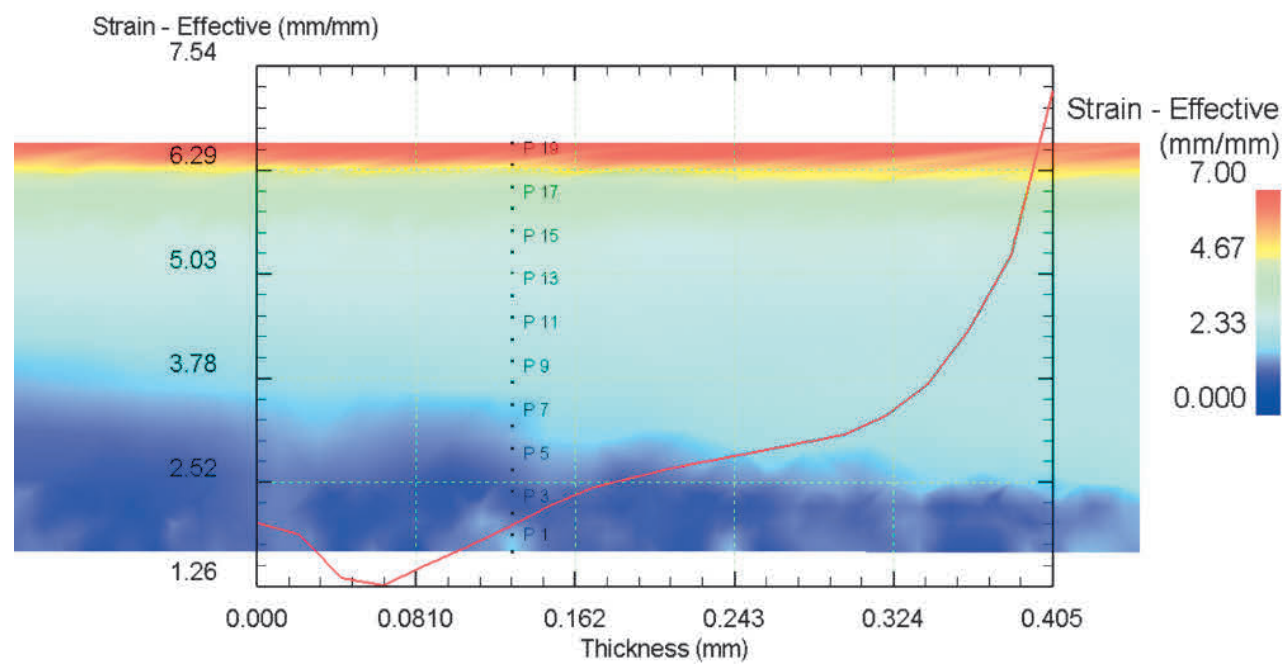

Figure 6 The distribution of effective strain through strip thickness after asymmetric rolling with smooth rolls

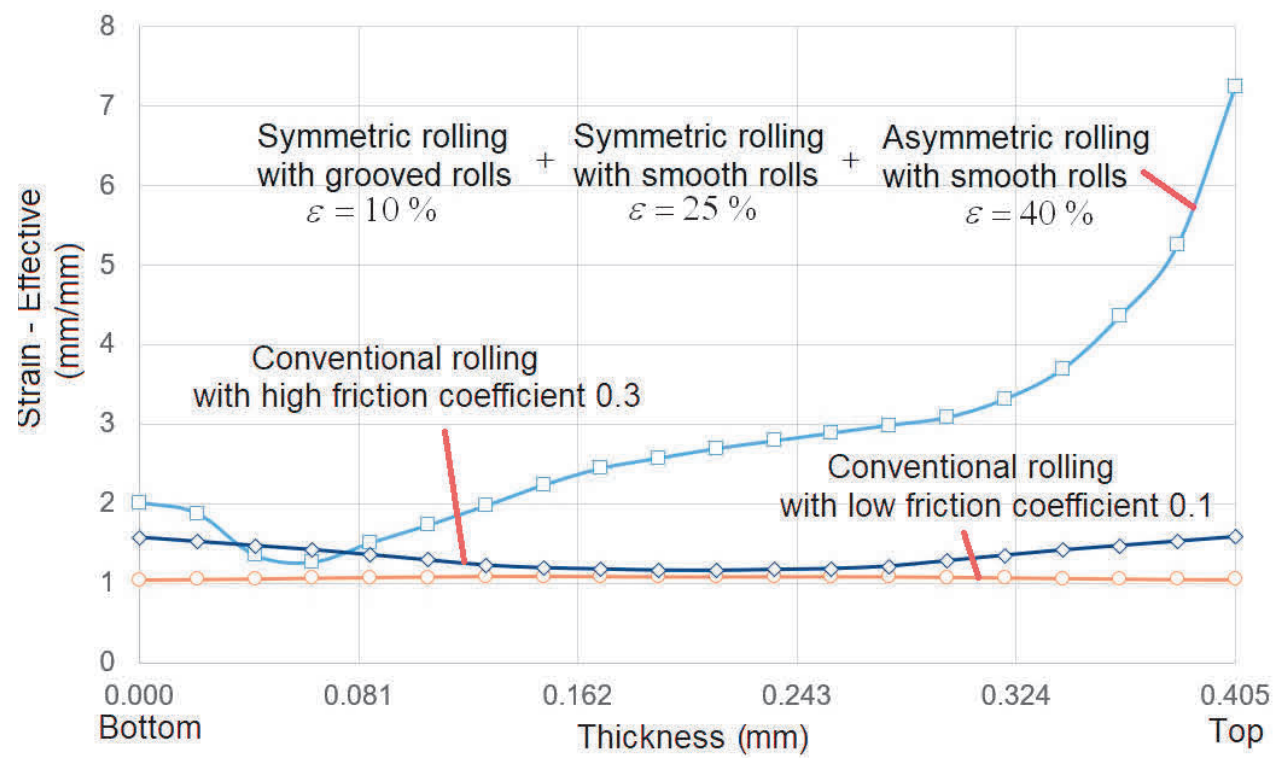

Figure 7 The distribution of effective strain through strip thickness during different strategies of rolling

\section{CONCLUSION}

The predetermined strain gradient through sheet thickness can be achieved by different strategies: 1) conventional (symmetric) rolling with high contact friction; 2 ) combined rolling process consisting of three deformation stages: symmetric rolling with grooved rolls + symmetric rolling with smooth rolls + asymmetric rolling with high rolls speed ratio and a high contact friction. The main disadvantage of the first strategy is a low strain gradient $e \approx 1.16 \ldots 1.57$. FEM simulations over a wide range of process parameters have shown, that extremely high strain gradient $e \approx 2.0 \ldots 7.2$ through sheet thickness can be reached by combined rolling process. Finite element analysis of strain gradients can be used for development of the special rolling techniques for fabrication of metal sheets with gradient structures and improved properties. Further experimental investigation of the rolling process is required. 


\section{ACKNOWLEDGEMENTS}

The study was supported by a grant of the Russian Science Foundation (contract No 15-19-10030) and by the Ministry of Science and Higher Education of the Russian Federation (grant of the President of the Russian Federation, contract No 075-02-2018-347 from 16.11.2018).

\section{REFERENCES}

[1] LIU, Z., MEYERS, M.A., ZHANG, Z. and RITCHIE, R. Functional gradients and heterogeneities in biological materials: Design principles, functions, and bioinspired applications. Progress in Materials Science. 2017. vol. 88, pp. 467-498.

[2] RITCHIE, R. The conflicts between strength and toughness. Nature Materials. 2011. vol. 10, pp. 817-822.

[3] YANG, X., WANG, X., LING, X. and WANG, D. Enhanced mechanical behaviors of gradient nano-grained austenite stainless steel by means of ultrasonic impact treatment. Results in Physics. 2017. vol. 7, pp. 1412-1421.

[4] HUANG, Y., WAN, L., LV, S., LIU, H. and FENG, J. Gradient micro-structured surface layer on aluminum alloy fabricated by in situ rolling friction stir welding. Materials and Design. 2013. vol. 52, pp. 821-827.

[5] CHEN, W., YOU, Z.S., TAO, N.R., JIN, Z.H. and LU, L. Mechanically-induced grain coarsening in gradient nanograined copper. Acta Materialia. 2017. vol. 125, pp. 255-264.

[6] LU, K. Making strong nanomaterials ductile with gradients. Science. 2014. vol. 345, pp. 1455-1456.

[7] FANG, T.H., LI, W.L., TAO, N.R. and LU, K. Revealing extraordinary intrinsic tensile plasticity in gradient nanograined copper. Science. 2011. vol. 331, pp. 1587-1590.

[8] ZHANG, W., HUO, W.T., LU, J.W., HU, J.J., WEI, Q. and ZHANG, Y.S. Gradient shear banding in a magnesium alloy induced by sliding friction treatment. Vacuum. 2017. vol. 143, pp. 95-97.

[9] LU, K. and LU, J. Nanostructured surface layer on metallic materials induced by surface mechanical attrition treatment. Materials Science and Engineering: A. 2004. vols. 375-377, pp. 38-45.

[10] LIU, M., LI, J.Y., MA, Y., YUAN, T.Y. and MEI, Q.S. Surface nanocrystallization and property of Ti6AI4V alloy induced by high pressure surface rolling. Surface and Coatings Technology. 2016. vol. 289, pp. 94-100.

[11] YU, H., LU, C., TIEU, A., LI, H., GODBOLE, A. and ZHANG, S. Special rolling techniques for improvement of mechanical properties of ultrafine-grained metal sheets: a review. Advanced Engineering Materials. 2015. vol. 18, pp. 754-769.

[12] KLOCKE, F., FELDHAUS, B. and MADER, S. Development of an incremental rolling process for the production of defined riblet surface structures. Production Engineering. 2007. vol. 1, pp 233-237.

[13] HIRT, G. and THOME, M. Rolling of functional metallic surface structures. CIRP Annals - Manufacturing Technology. 2008. vol. 57, pp. 317-320.

[14] GAO, Z.Y., PENG, L.F., YI, P.Y. and LAI, X.M. Micro/Meso Roll-to-Plate (R2P) Imprinting Process to Fabricate Micro Channel/Riblet Features. Applied Mechanics and Materials. 2013. vols. 271-272, pp. 611-616.

[15] SHIMOYAMA, K., YOKOYAMA, S., KANEKO, S. and FUJITA, F. Effect of grooved roll profiles on microstructure evolutions of AZ31 sheets in Periodical Straining Rolling process. Materials Science and Engineering: A. 2014. vol. 611, pp. 58-68.

[16] KUDO, S., YOKOYAMA, S., SHIMOYAMA, K., KANEKO, S. and FUJITA, F. Effect of dimple patterning conditions of Periodical Straining Rolling on microstructures and mechanical properties of AZ31 sheets. Materials Science and Engineering: A. 2017. vol. 680, pp. 75-84.

[17] PESIN, A. and PUSTOVOYTOV, D. Influence of process parameters on distribution of shear strain through sheet thickness in asymmetric rolling. Key Engineering Materials. 2014. vols. 622-623, pp. 929-935.

[18] PESIN, A. and PUSTOVOYTOV, D. Finite element simulation of extremely high shear strain during a single-pass asymmetric warm rolling of Al-6.2Mg-0.7Mn alloy sheets. Procedia Engineering. 2017. vol. 207, pp. 1463-1468.

[19] ROUMINA, R. and SINCLAIR, C.W. Deformation geometry and through-thickness strain gradients in asymmetric rolling. Metallurgical and Materials Transactions A. 2008. vol. 39, pp. 2495.

[20] YU, H., TIEU, K. and LU, C. Advanced rolling technologies for producing ultrafine-grain/nanostructured alloys. Procedia Engineering. 2014. vol. 81, pp. 96-101. 